\title{
INTERDISCIPLINARIDADE NA ESCOLA: SUBSÍDIOS PARA UMA ZONA DE DESENVOLVIMENTO PROXIMAL COMO ESPAÇO SIMBÓLICO'
}

RESUMO: Este artigo visa a contribuir com subsídios teórico-empíricos sobre a concepção de Zona de Desenvolvimento Proximal (ZDP) como um espaço simbólico, de mediação semiótica, apresentada por Meira e Lerman (2010). Tais subsídios são extraídos da análise de uma pesquisa realizada por duas professoras-pesquisadoras, uma de Matemática, a outra de Ciências, de uma mesma turma de alunos do nono ano do Ensino Fundamental de uma escola pública de Belo Horizonte. Nesta pesquisa, executou-se um trabalho interdisciplinar entre as duas professoras, em que se investigou como e sob quais circunstâncias tal trabalho poderia encorajar os alunos a "cruzar as fronteiras" das duas disciplinas. A partir da ilustração de dois episódios de aprendizagem, a noção de ZDP como espaço simbólico é reforçada e a questão da fragilidade e da instabilidade de uma ZDP é discutida.

Palavras-chave: Interdisciplinaridade. Zona de Desenvolvimento Proximal. Linguagem. Educação Matemática. Educação em Ciências.

\footnotetext{
* Doutora em Educação pela Universidade Federal de Minas Gerais (UFMG) e Professora no Programa de Pós-graduação em Educação da Universidade Federal de Minas (UFMG). E-mail: frade.cristina@gmail.com

** Ph.D. em Educação Matemática pela University of California at Berkeley e Professor Adjunto do Departamento de Psicologia da Universidade Federal de Pernambuco (UFPE). E-mail: luciano@meira.com
} 


\section{AN INTERDISCIPLINARY APPROACH IN SCHOOLS: ELEMENTS FOR CREATING A ZONE OF DEVELOPMENT IN PROXIMITY, AS A SYMBOLIC SPACE} ments to the conceptualization: the Zone of Development in Proximity (ZDP), as a symbolic space that has a semiotic aspect (that mediates meaning of language and symbols), as proposed by Meira and Lerman (2010). Such elements are derived from the analysis of an interdisciplinary piece of research carried out by two teacher-researchers one a mathematician, the other a scientist, both teaching the same year nine secondary class, at a public school in Belo Horizonte, Brazil. This analysis shows how, and under which circumstances, such interdisciplinary work challenges or encourages the students to "cross the boundaries" between the two disciplines. Based on two learning episodes, the notion of ZDP as a symbolic space is reinforced, and the fragility and instability of ZDPs are discussed.

Keywords: Interdisciplinary. Cross-curricular. Zone of Development in Proximity. Language. Mathematics Education. Science Education.

\section{Introdução}

Este artigo tem como objetivo contribuir com subsídios teóricoempíricos sobre a concepção de Zona de Desenvolvimento Proximal (ZDP) como um espaço simbólico, como a concebem Meira e Lerman $(2010)^{2}$. Sendo assim, não é nosso propósito oferecer uma revisão extensa da literatura sobre o construto ZDP formulado por Vygotsky (1978). Tal revisão poderia direcionar o objetivo do texto para outras questões além daquelas que nos propomos discutir. Além disso, correríamos, inevitavelmente, o risco de repetir elementos da refinada e pontuada revisão desse construto encontrada no referido trabalho de Meira e Lerman ou de revisões mais abrangentes, já realizadas por outros pesquisadores (p. ex., VAN DER VEER; VALSINER, 1991; FINO, 2001; DANIELS; WERTSCH; COLE, 2007). Alternativamente, detemo-nos a retomar o que constituem, a nosso ver, os pontos principais da interpretação de Meira e Lerman sobre uma ZDP corresponder a um espaço simbólico, de mediação semiótica, bem como aspectos de suas investigações empíricas.

Feito isso, descrevemos o contexto de uma pesquisa interdisciplinar realizada por duas professoras-pesquisadoras, uma de Matemática ${ }^{3}$ e a outra de Ciências, de uma mesma turma de alunos do nono ano (antiga oitava série) do Ensino Fundamental de uma escola pública de Belo Horizonte. Nessa pesquisa, examinou-se como e sob quais circunstâncias 
tal colaboração poderia encorajar os alunos da turma a "cruzar as fronteiras" das duas disciplinas.

Uma primeira análise desta pesquisa foi realizada por Frade, Winbourne e Braga (2009), na qual se propõe, em detalhes, uma topologia (configuração e características) para o ambiente de aprendizagem que deu origem ao fenômeno "cruzamento de fronteiras" em termos do conceito de comunidades de prática (LAVE, 1988; LAVE; WENGER, 1991; WENGER, 1998) e das ideias e da pedagogia de Bernstein (1996, 2004) sobre fronteiras das disciplinas ou práticas escolares. No presente artigo, procuramos avançar nessa análise ao oferecer uma interpretação semiótica para o fenômeno, baseando-nos na noção de ZDP como um espaço simbólico, tal como Meira e Lerman a concebem.

Em seguida, apresentamos dois episódios de aprendizagem: o primeiro em que Aline é a personagem central, o segundo em que a personagem central é Júlia, para subsidiar tal noção de ZDP. Também discutimos a questão da fragilidade e da instabilidade de uma ZDP, considerando ambos os contextos de investigação desses pesquisadores e das referidas professoras-pesquisadoras de Matemática e de Ciências. Por fim, tecemos algumas considerações sobre nossas análises.

\section{Reflexões sobre a Zona de Desenvolvimento Proximal no contexto escolar}

O conceito de Zona de Desenvolvimento Proximal, elaborado por Vygotsky em Mind in Society ${ }^{4}$ (1978), para explorar relações entre educação e desenvolvimento, é comumente associado à distância existente entre o nível de desenvolvimento real e o nível de desenvolvimento potencial (ou possível) de aprendizagem dos indivíduos. O nivel de desenvolvimento real refere-se ao nível no qual um indivíduo é capaz de resolver problemas sozinho (ainda que equivocadamente) e o nivel de desenvolvimento potencial designa o nível em que esse indivíduo precisa da mediação de outro indivíduo ou da colaboração de outros indivíduos mais competentes (numa determinada habilidade) para avançar na aprendizagem ou ampliar seus conhecimentos. Uma vez internalizados, esses conhecimentos se tornam parte do desenvolvimento de cada indivíduo.

Assim como Meira e Lerman (2010), entendemos que tal associação, sozinha, não é suficiente para expressar o escopo da noção de 
ZDP formulada por Vygotsky. Meira e Lerman mostram que podemos identificar três formulações ou fases no desenvolvimento dessa noção nos trabalhos de Vygostky, vinculadas, nessa ordem, ao desempenho, à interação e à mediação simbólica. A vinculação ao desempenho representa uma crítica aos tradicionais testes de QI e uma tentativa de comparar diferentes patamares entre os desempenhos individuais e assistidos na resolução de problemas. A vinculação à interação é uma extensão da primeira fase, porém priorizando os aspectos sociais de assistência e suporte em detrimento da avaliação de desempenho $0^{6}$. Por fim, a vinculação à mediação semiótica vai além da situação sociointeracional imediata, enfocando mais o mundo mediado simbolicamente que permeia a situação ou as atividades de resolução de problemas. Meira e Lerman (como também HAZIN; MEIRA, 2004) posicionam sua perspectiva sobre a noção de ZDP no âmbito das segunda e terceira formulações, em conjunção. Tal posição é a mesma adotada no presente artigo.

Ampliando o entendimento de educação para além dos muros da escolarização formal, e pensando nas múltiplas interações sociais de que participamos no mundo, percebemos o quanto estamos em contínuo processo de aprendizagem uns com os outros, seja qual for a esfera considerada - formal, informal ${ }^{7}$ ou cognitivo-afetiva. Em muitas dessas interações, mudamos nossa maneira de pensar e/ou agir em relação ao que pensávamos e/ou agíamos antes. Ora, se somos capazes de pensar e/ou agir de forma diferente do que fazíamos antes, é porque nos tornamos uma pessoa diferente, no sentido de que aprendemos e desenvolvemos em certo domínio. E se isso acontece não é porque interagimos pelo mero ato de interagir, mas, sim, porque nos deixamos envolver e envolvemos outros em atos comunicativos. Isso já seria o bastante para refletirmos o quão potencial é o conceito de ZDP de Vygostky, descrito conforme as formulações acima, para explicar como ensinamos, aprendemos e nos desenvolvemos como seres humanos.

No contexto escolar, a sala de aula é um ambiente particularmente fértil e profícuo para a produção de ZDPs, isto é, para a produção de movimentos de aproximação do nível de desenvolvimento real de competências, em relação a determinados conhecimentos/habilidades, para o nível de desenvolvimento potencial de indivíduos. Isso porque uma sala de aula é supostamente configurada tendo-se em mente um ambiente onde haverá uma inter-relação entre ensino e aprendizagem. E esse 
ensino é, supostamente, atribuído a professores que possuem mais experiência nesses conhecimentos do que aqueles que supostamente vão aprendê-los - os alunos. Ora, se a sala de aula não cumpre essa função, qual seja, a de levar os alunos a progredirem de certo nível de entendimento para outro, então sua existência não faz sentido. Como professores, acreditamos que, na sala de aula, é perfeitamente possível conseguir isso, ainda que nem todos progridam no mesmo ritmo ou mesmo que nem todos sejam "motivados" de uma vez só para a aprendizagem. Acreditamos também que ZDPs possam emergir sem que tenhamos ciência delas. Por outro lado, dizer que a sala de aula é um local profícuo para a emergência de ZDPs não quer dizer que ela é o único ambiente profícuo para a emergência de ZDPs, ou mesmo que tal emergência se dê de fato.

Dito isso, os agentes da produção de (possíveis e desejáveis) ZDPs em salas de aula são os alunos e seus professores (e eventualmente outros, por exemplo, estagiários e monitores). Os professores são aqueles agentes mais capazes (no que diz respeito ao conhecimento das disciplinas que ministram) para desempenhar o papel de mediadores das interações entre alunos e entre alunos e os objetos do conhecimento, de modo a contribuir para que ocorram avanços ou progressos na aprendizagem deles. Quando o professor, por exemplo, faz uma pergunta para os alunos e eles respondem, essas respostas, que podem ser diferentes, estão no nível de desenvolvimento real desses alunos; eles respondem aquilo que já sabem ou acreditam saber, mesmo que suas respostas sejam consideradas erradas sob o ponto de vista da disciplina. Se nada acontece por parte do professor (ou mesmo de outros alunos), aqueles que responderam ao professor talvez permaneçam com as mesmas ideias que os levaram a expressar suas respostas. Mas, se o professor (ou esse outro aluno) consegue produzir um entendimento e atuar nas respostas dos estudantes com ações que os façam avançar ou progredir em suas ideias iniciais, argumentamos, então, que uma ZDP emergiu, provocando, assim, uma mudança no nível real dos alunos para o nível potencial. Se tal avanço ou progressão, por sua vez, leva os alunos a produzir novos entendimentos no âmbito dessas "novas" ideias, então o nível potencial alcançado tornase real e, neste caso, dizemos que uma aprendizagem ocorreu. E, consequentemente, esses alunos podem mostrar progresso em algum domínio. Mais ainda, isso somente foi possível em função da situação ou atividade 
sociointeracional produzida dentro de um ambiente semiótico. Em outras palavras, tal avanço ou progressão não se antecipa a uma situação ou atividade, como se a ZDP fosse um espaço "quase físico", que cada aluno possui e que o professor precisa apenas descobri-lo para tornar seu ensino bem-sucedido (NEWMAN; HOLZMAN, 1993). Ao contrário, esses avanços e progressões são situados, no sentido de que emergem como frutos de atos comunicativos mediados simbolicamente. É dessa maneira que, no contexto da sala de aula, compreendemos o funcionamento dos mecanismos de aprendizagem da ZDP, segundo Vygotsky (e, com certeza, o exemplo acima não exaure as inúmeras possibilidades de produção de ZDPs na sala de aula, como discutem HAZIN; MEIRA, 2004).

A essa altura, seria possível sugerir que a sala de aula, como a conhecemos, está longe de ser um ambiente particularmente fértil para a emergência de ZDPs, pois sabemos quão pouco essa dinâmica realmente ocorre nas escolas. De nossa experiência como professores-pesquisadores, atribuímos grande parte do problema à formação institucional do professor, à escassez de reflexão sobre sua prática, à sensibilidade e à competência do professor em fazer perguntas do tipo: "como meus alunos aprendem?" ou “eles estão aprendendo?"

Diante do exposto, cabe então perguntar: como identificar uma ZDP em interações em sala de aula?

\section{A noção de ZDP como um espaço simbólico, segundo Meira e Lerman}

Meira e Lerman (2010) oferecem uma resposta a essa questão. Tal resposta é particularmente significativa para os objetivos do presente artigo, na medida em que relataremos outra pesquisa, realizada em outro contexto, por duas professoras-pesquisadoras, uma de Matemática e outra de Ciências, na qual serão produzidas evidências que subsidiam/reforçam a perspectiva teórico-empírica presente na resposta desses pesquisadores. É por essa razão que nos atemos a descrever as ideias de Meira e Leman e aspectos de suas investigações empíricas.

Primeiro, para Meira e Lerman, a noção de ZDP toma uma direção teórica totalmente oposta à da noção de um espaço "quase físico", como aludido anteriormente. A direção que eles adotam concorre, como eles próprios declaram, com as direções de Newman e Holzman (1993) e 
de Van der Veer e Valsiner (2001), segundo as quais a ZDP é um espaço intersubjetivo mediado por signos ${ }^{8}$, que emerge (ou não) na instrução ou em interações dialógicas de qualquer natureza, dentro do qual ocorrem o cultivo social de processos ainda não desenvolvidos e a construção, pelos indivíduos, de estruturas futuras de suas funções intelectuais sob as bases de suas experiências passadas. Com base nessa formulação, Meira e Lerman enfatizam três aspectos principais: o primeiro se refere ao fato de que a ZDP não é algo preexistente a um evento ou atividade; ela é um fenômeno continuamente emergente. $\mathrm{O}$ segundo aspecto relaciona-se à proposição de que ver a ZDP como um espaço simbólico nos capacita a mudar o foco para além do indivíduo per se em direção à emergência de modos de comunicação. $\mathrm{O}$ terceiro diz respeito à relação entre aprendizagem e desenvolvimento: a ZDP é um espaço simbólico para interações e comunicações, no qual a aprendizagem conduz o desenvolvimento.

A partir dessas ideias, Meira e Lerman propõem que investigações empíricas sobre a ZDP, em salas de aula, incidam o foco não apenas nas interações sociais caracterizadas pela assistência aos alunos, por parte do professor, mas, sobretudo, nas "trocas" semióticas emergentes nessas interações. Para tal, os autores desenvolveram um instrumento de análise para interpretar as falas e os gestos dos professores e dos alunos em termos de contribuições discursivas que oferecem significados públicos para se agir sobre e serem apropriados na interação. De acordo com Meira e Lerman, essas contribuições discursivas podem ser de dois tipos9:

Linguagem orientada a conteúdos, centrada em tópicos reconhecidos pelo próprio professor como pertinentes aos conteúdos do currículo;

Linguagem orientada à comunicação, voltada para intervenções feitas pelo professor, que orientam o aluno em direção a um novo estágio de sua vida escolar; ou intervençoes feitas pelo aluno ou pelo professor, por meio de falas ou gestos, visando (i) à redução de lacunas comunicativas e ambiguidades na fala, (ii) à autorregulação, (iii) à chamada/solicitação por atenção, e (iv) à construção de relações entre eventos ou ações passadas, presentes e futuras. ${ }^{10}$

Meira e Lerman observam que todo ensino está relacionado a algum conteúdo e, como tal, a linguagem orientada à comunicação também ocorre dentro dos domínios de conteúdos específicos. Contudo, essa última forma de linguagem diz respeito, mais notadamente, a comportamentos ou normas sociais escolares e modos de comunicação na sala de aula. Por outro lado, continuam os autores, a primeira forma de linguagem 
(orientada a conteúdos) não leva, necessariamente, à comunicação (no sentido de reciprocidade com que essa noção tem sido aqui usada), por exemplo, em salas de aula em que o conteúdo é transmitido por via única: a da exposição do professor.

Para Meira e Lerman, então, a ZDP tem dois sentidos: o primeiro, como espaço simbólico para o ensino e a aprendizagem. O segundo, complementar ao primeiro, a ZDP é uma ferramenta analítica com a qual podemos analisar "a microgênese de eventos e atividades emergentes em sala de aula; ela dá suporte aos significados que criamos a partir de vídeos e transcrições (...). Assim, a ZDP é, ao mesmo tempo, um resultado/produto e uma ferramenta dentro das análises vygostkyanas de desenvolvimento" (MEIRA; LERMAN, 2010, p. 205).

Usando a concepção de ZDP como espaço simbólico, em termos dos dois tipos de contribuições discursivas descritas acima, Meira e Lerman analisam a interação entre uma professora e seus alunos de préescola. Em um dos eventos analisados, os autores investigam os movimentos comunicativos da professora e de um aluno em torno de uma plantação de feijões em algodão, mostrando como eles sustentam um campo atencional compartilhado, no qual ambos se tornam progressivamente mais capazes de se comunicarem, reconhecendo a ambiguidade de suas próprias contribuições discursivas, dado que a professora se posiciona de maneira receptiva às tentativas da criança de usar novas palavras, de maneiras diferentes.

A seguir, passamos à descrição do contexto da pesquisa interdisciplinar realizada pelas professoras-pesquisadoras de Matemática e Ciências.

\section{Um trabalho interdisciplinar entre Matemática e Ciências na escola}

Cristina e Selma realizaram uma pesquisa numa turma de 28 alunos (com idades aproximadas de 14 anos) do nono ano do Ensino Fundamental de uma escola da rede de ensino público de Belo Horizonte, na qual ministravam aulas de Matemática e Ciências, respectivamente ${ }^{11}$. Cristina dava aulas para essa turma desde o oitavo ano (antiga sétima série). O objetivo da pesquisa foi investigar como e sob quais circunstâncias tal trabalho colaborativo poderia motivar os alunos a cruzar as fron- 
teiras entre essas disciplinas. Os conceitos escolhidos pelas professoraspesquisadoras foi proporcionalidade, em Matemática, e densidade, em Ciências. Essa escolha deveu-se ao pressuposto de que, embora proporcionalidade e densidade sejam instâncias de uma mesma ideia matemática, a correspondência entre tais conceitos provavelmente não seria reconhecida pelos alunos. A intenção das professoras foi, então, produzir um ambiente de aprendizagem em Matemática e Ciências em que os alunos pudessem compreender essa correspondência, isto é, que a densidade de um material homogêneo é a razão de proporcionalidade entre massa e volume ou, ainda, que massa e volume são grandezas diretamente proporcionais. Dessa maneira, as professoras-pesquisadoras planejaram, também, contribuir para o desenvolvimento do raciocínio dos alunos sobre o que Howe, Nunes e Bryant (2005) denominam grandezas intensivas (intensive quantities): duas variáveis relacionadas pela lógica da co-variação.

Cristina e Selma gastaram um tempo considerável - uma média de duas horas por semana, entre os meses de junho e novembro de 2005 - planejando e organizando os materiais e atividades para a turma. Essas ações envolveram leituras individuais e conjuntas de materiais matemáticos e científicos planejados para oferecer aos alunos discussões desses materiais, esforços por parte das duas colegas para alinhar as especificidades de linguagem de suas disciplinas, e discussões de como e quando "pontes" poderiam ser construídas entre essas disciplinas. Tais interações ocorreram na escola, na casa de Selma, em horários de almoço e por meio de muitas ligações telefônicas e conversas no Skype, a maioria delas fora do horário de trabalho. Algumas dessas interações foram registradas por escrito; outras foram registradas em vídeo. Quando Cristina e Selma tinham alguma ideia nova sobre o trabalho colaborativo, não importava a hora ou o dia, elas se comunicavam. É significativo dizer que as duas colegas são muito amigas e compartilham valores educacionais.

No currículo da escola proposto para o nono ano, sugeria-se que os alunos estudassem proporcionalidade antes de estudarem densidade. Por essa razão apenas, Cristina iniciou as atividades de pesquisa com sua turma antes de Selma. As atividades de proporcionalidade começaram em agosto de 2005; as atividades de densidade começaram dois meses mais tarde.

Cristina preparou um texto interativo para os alunos sobre proporcionalidade direta, o qual, entre outras questões, convidava os alunos a discutir algumas "razões especiais". Após introduzir e exemplificar o 
conceito de razão como quociente de dois números, o texto enfatizava que velocidade, densidade demográfica, consumo de energia durante um período de tempo e Pi $(3,1416 \ldots)$ eram exemplos dessas razões especiais, e perguntava aos alunos: "Você sabe o que essas razões significam?", "Você conhece outras razões especiais?". Para trabalharem no texto e nos exercícios que se propunha, os alunos foram divididos em pequenos grupos (4 ou 5, no máximo). Quando os grupos terminaram o trabalho, Cristina encorajou-os a falar sobre ele. A atividade de proporcionalidade durou quatro horas-aula de 50 minutos cada uma. Os dados para nossa análise foram produzidos a partir dos exercícios escritos pelos alunos, de registros em vídeo das discussões dos grupos e de registros em vídeo de entrevistas com alguns alunos e com dois estudantes de graduação que estavam realizando estágio na sala de aula da professora.

Selma ministrou oito horas-aula de 50 minutos sobre o tópico de densidade. Aqui, os alunos trabalharam em atividades propostas por uma apostila interativa sobre densidade e realizaram atividades de laboratório em pequenos grupos, nas quais calcularam a densidade de alguns materiais e fizeram experimentos para verificar a relação entre densidade e flutuação desses materiais na água. Durante cada um desses experimentos, Selma dizia "afunda e flutua, estão vendo?", e os alunos se divertiam com isso, pois muitos deles repetiam "afunda e flutua". As atividades de Ciências foram registradas em vídeo e os exercícios escritos pelos alunos foram recolhidos. Durante todas as aulas sobre densidade, Selma chamou a atenção dos alunos para o fato de que o conceito matemático por trás de densidade era o de proporcionalidade, que havia sido trabalhado, recentemente, nas aulas de Cristina. Ao fazer isso, ela revisou o conceito de proporcionalidade - alguma coisa como ela já havia planejado com sua colega que faria - ajustando seu discurso científico o tanto quanto pode para aproximá-lo do discurso matemático de Cristina.

Antes de iniciar a produção dos dados, as duas professoras conversaram com os alunos em sala de aula e, em linhas gerais, sobre a pesquisa, seus objetivos e procedimentos. Porém, não foi discutido com os alunos o foco específico da pesquisa. Tais conversas tiveram a intenção de se obter alto grau de participação dos alunos e encorajá-los a se tornarem agentes ativos da prática colaborativa que as professoras-pesquisadoras almejavam produzir. Nas próximas seções, os nomes dos alunos são fictícios. Nossas observações são colocadas entre colchetes. 


\section{Os episódios de aprendizagem: Aline e Júlia}

A história de Aline começa após o trabalho em grupo sobre proporcionalidade ter sido corrigido cuidadosa e coletivamente. A turma, juntamente com a professora, discutiu sobre as razões especiais e Cristina fez notas detalhadas dessas razões na lousa. Ela perguntou aos alunos se eles conheciam outras razões especiais. Aline disse densidade e, logo em seguida, vários alunos também disseram o mesmo. Cristina perguntou, então, o que eles entendiam por densidade e esses alunos, quase que ao mesmo tempo, responderam massa dividida por volume. A professora voltouse a Aline e pediu-lhe que falasse um pouco mais sobre a conexão entre proporcionalidade e densidade. Aline não foi capaz de fazer isso; sua face mostrou uma expressão de dúvida. A professora, então, estimulou uma discussão com os alunos sobre as densidades da água, do ferro, da gasolina e de outros materiais físicos, enfatizando (e ilustrando) o fato de que, para cada um desses materiais, a densidade é a constante de proporcionalidade direta entre massa e volume. Como Selma havia feito, Cristina também motivou a discussão sobre essa conexão, tentando ajustar seu discurso matemático ao discurso científico que Selma revelava nas aulas de Ciências. ${ }^{12}$

Ao final da aula, Cristina solicitou a Aline e mais dois alunos Henrique e Carolina - que conversassem com ela numa entrevista. Entre outras coisas, ela perguntou aos alunos quando eles haviam, primeiramente, identificado densidade como sendo uma razão especial; se foi no dia em que eles trabalharam no texto em grupo ou no dia em que corrigiram seus trabalhos coletivamente. Todos os três alunos disseram que fizeram tal conexão no dia da correção coletiva, como mostram as transcrições:

Aline: Eu já tinha estudado isso em Química. Ai eu vi as razões. Então, quando comparei isso com as rãões que estavam no quadro-negro [lousa] ontem, aceleração [por exemplo], ai eu lembrei de densidade.

Henrique: Eu acho que foi mais porque a discussão foi mais aberta. Eu acho que isso ajudou. Todo mundo dando uma opinião, dizendo alguma coisa; ai lembrando um pouquinho aqui, um pouquinho ali.

Carolina: Foi porque eu vi ela [Aline] falando. Eu só lembrei quando ela falou. 
A fala de Aline, Ai eu vi as razões, parece marcar o momento em que ela fez a conexão entre o que antes parecia dois conceitos não relacionados. $\mathrm{O}$ restante de sua fala indica que cruzou as fronteiras das duas disciplinas: primeiro ela reconhece que já havia estudado densidade em Química, e então ela sugere que densidade é um caso particular de proporcionalidade. $\mathrm{O}$ que Aline e outros alunos pareceram não saber era que, para um material físico específico, massa e volume estavam em relação de proporcionalidade.

Por outro lado, as falas de Henrique e Carolina sugerem uma cadeia semiótica que "desliza" significados entre o discurso matemático e o discurso científico (EVANS, 2000). Conforme apontam Meira e Pinheiro (2007), tais "deslizes" são típicos do processo de produção de sentidos e podem ser interpretados como um "trânsito linguístico" entre os vocabulários próprios a cada um desses domínios. Essa sugestão nos leva a supor que a conexão realizada entre proporcionalidade e densidade, tanto na sala de aula de Matemática quanto nas entrevistas com Cristina, foi mais do que uma conquista somente de Aline: as falas de Henrique e Carolina mostram que um processo ligando esses conceitos emergiu de atos comunicativos na sala de aula. Desse modo, o cruzamento de fronteiras entre as disciplinas Matemática e Ciências, associado à conexão proporcionalidade-densidade, não foi uma conquista apenas individual. Ao contrário, vemos tal processo como um aspecto de um fenômeno coletivo produzido por uma prática que envolveu Aline, Henrique, Carolina e outros alunos que ecoaram Aline ao dizerem densidade na aula de Matemática.

Mais adiante na entrevista, Cristina perguntou a Aline, Henrique e Carolina se eles já haviam trabalhado com densidade antes. Todos eles disseram que sim, em dois contextos diferentes: quando eles estavam no sexto ano (antiga quinta série, cuja professora, coincidentemente, foi Selma) e, recentemente, num cursinho particular que eles estavam fazendo para se prepararem para entrar numa escola do Ensino Médio. Todos os três alunos comentaram, voluntariamente, que Selma não gostava de fórmulas, que ela preferia trabalhar com o entendimento. Eles contrastaram a abordagem de Selma com os métodos procedurais do cursinho: isso é pra isso, aquilo é praquilo e você tem que usar isso [a fórmula de densidade] assim!, disse Henrique. É interessante notar que esses alunos reconheceram que haviam aprendido coisas (aparentemente) diferentes, embora com o mesmo rótulo, nos dois cenários. 
A história de Júlia começa durante uma visita técnica, planejada por Selma, a uma usina hidrelétrica, na ocasião em que os alunos estavam estudando densidade nas aulas de Ciências. O objetivo dessa visita foi levar os alunos a conhecerem e observarem as fases do processo de transformação de energia in loco. A primeira parada que a turma fez foi numa represa (lago). A tarefa deles era, na verdade, observar como a água passava através das comportas construídas para regular o fluxo de água que entrava em um canal. Lamentavelmente, quando os alunos se aproximaram da represa, eles se depararam com o corpo de um cachorro morto flutuando na água. O corpo flutuava entre pedaços de papel, garrafas de plástico, pedaços de madeira e outros dejetos. Essa cena causou espanto e desagrado nos alunos. Alguns deles começaram a se perguntar como o cachorro - presumivelmente um bom nadador - havia morrido afogado. Outros ficaram perturbados pela observação da professora de que a atitude de muitos brasileiros em relação ao meio ambiente ainda fazia com que os rios virassem depósitos de lixo. De repente, Júlia exclamou: afunda e flutua!. Como ocorreu com Aline, essa fala parece marcar o momento em que Júlia fez uma conexão entre duas questões curriculares de Ciências, aparentemente, não relacionadas: densidade (corpo flutuante do cachorro morto) e meio ambiente (rios como depósitos de lixo). Isso surpreendeu Selma cuja agenda não era mais, nessa ocasião, discutir densidade, mas, sim, os processos de transformação de energia. Contudo, ela se aproveitou da observação de Júlia para reviver as conversas sobre "afunda e flutua", e novas discussões surgiram em torno da pergunta da professora: "Por que todos esses materiais estão flutuando?" Os alunos não demonstraram nenhuma dificuldade em recordar seus estudos sobre densidade. Um aluno disse: "É porque eles são menos densos que a água". Outros reagiram: "Mas e o corpo do cachorro morto, por que flutua?" Selma e os alunos conversaram sobre o corpo do cachorro morto e aplicaram o que haviam aprendido sobre densidade nas aulas de laboratório. Aqui, novamente, temos uma sugestão de que uma cadeia semiótica "disparada" por Júlia, "deslizando" significados sobre a densidade, pode ter emergido no contexto de uma questão ambiental. Selma também estendeu a conversa de tal modo a discutir, além da relação "afunda e flutua", outras e "novas" (para os alunos) relações, tais como a flutuação de corpos humanos e a fisiologia dos pulmões. Essa conversa tomou conta de boa parte da visita e, segundo a professora, todos os alunos se engajaram na conversação, de uma forma ou 
de outra. A história termina com Selma de volta à escola com a turma, referindo-se, mais uma vez, aos eventos ocorridos na hidrelétrica sobre "afunda e flutua".

De maneira similar ao que foi descrito na história de Aline, a professora usou o comentário "afunda e flutua" de Júlia para transpor as fronteiras das duas questões de Ciências, mencionadas anteriormente; sem tal intervenção, essas questões poderiam permanecer desconectadas dentro do espaço discursivo da disciplina. Também, como no caso de Aline, o cruzamento de fronteiras entre os tópicos densidade e meio ambiente não foi uma conquista apenas de Júlia, mas, sim, de um grupo que envolveu Júlia e outros alunos que se engajaram prontamente na "chamada" da professora para darem sequência ao comentário de Júlia.

O que poderia ter levado Aline e Júlia (e possivelmente outros) a fazerem tais conexões? Por que outros alunos se engajaram tão rapidamente nas conversações que se seguiram a essas conexões?

\section{Identificando ZDPs como espaços simbólicos nos episódios de Aline e de Júlia}

Respostas às questões acima podem ser elaboradas com base na interpretação de Meira e Lerman (2010) acerca da ZDP como um espaço simbólico. Mais precisamente, propomos ver uma ZDP como um resultado emergente das atividades desenvolvidas no trabalho colaborativo das duas professoras-pesquisadoras, atividades nas quais fazer conexões era o principal objetivo instrucional de ambas as professoras. Em termos da proposta de Meira e Lerman, a prática interdisciplinar criada pode ser vista como um espaço que emergiu em instrução por meio de interações discursivas, notadamente do tipo linguagem orientada a conteúdos, que foram compartilhadas e reguladas pelos participantes (alunos e professoras), proporcionando possibilidades para relações passado-presente-futuro em ambos os discursos matemático e científico dos alunos e formas de comunicá-los. Essas relações indicam como os alunos participantes marcam, em seus discursos, aspectos contextualmente relevantes de suas interações. Nossa interpretação é que os comentários feitos por Aline, Henrique, Carolina (e outros) quando conectaram ideias de densidade nas aulas de Matemática (presente) ao estudo de Química (passado), como 
também suas comparações, durante a entrevista com Cristina, entre o modo como Selma ensinava no sexto ano (passado) e o modo como se ensinava no cursinho preparatório para o Ensino Médio (presente), são exemplos de tais relações temporais. Da mesma maneira, na descrição do episódio de Júlia, argumentamos que a discussão do evento "afunda e flutua" na usina hidroelétrica contém evidências dessas relações: os alunos participantes se engajam numa conversação, disparada por Júlia e guiada por Selma, que relaciona o corpo flutuante do cachorro morto (presente) com ideias de densidade ensinadas no laboratório de Ciências da escola (passado).

No que diz respeito às relações futuras, que são, a nosso ver, a chave do potencial de realização da ZDP, como concebida por Vygotsky, produzimos indícios do que poderíamos chamar de "germes" ou "sementes" dessas relações. Por exemplo, na história de Aline, após ela (e outros alunos que a seguiram) ter dito "densidade", Cristina aproveitou a situação para discutir a densidade de alguns materiais físicos homogêneos, tais como, a água, a gasolina e o ferro, como já mencionado. Cristina perguntou aos alunos se eles sabiam qual era a densidade da água, o que muitos responderam: "um (1)". A professora perguntou então Um quê? e alguns responderam um grama por centímetro cúbico. Cristina discutiu com eles o que significava essa razão e a aluna Elaine respondeu que em um centímetro cúbico havia um grama de água. A professora continuou, perguntando à turma se alguém sabia o que significava um centímetro cúbico em termos de unidade de volume. Não obtendo nenhuma resposta, dirigiu-se à lousa, desenhou um cubinho marcando $1 \mathrm{~cm}$ em cada aresta e falou que um centímetro cúbico correspondia ao volume de um cubinho de um centímetro de aresta. Em seguida, disse e escreveu na lousa que a densidade da gasolina era 0,7 gramas por centímetro cúbico (tudo isso ela sabia porque havia conversado com Selma antes e se preparado para tal discussão, caso ela aparecesse). Daí, perguntou: Dá para dizer qual material é mais denso, a água ou a gasolina? Vários alunos responderam: $A$ água. A conversa continuou como mostra o protocolo a seguir.

Cristina: Em termos físicos, se eu misturar a água com a gasolina, o que acontece? A densidade vai fazer o quê?

Amanda: Um vai ficar na parte de baixo e o outro, na parte de cima. 
Cristina: Quem vai ficar na parte de cima? E na de baixo?

Alguns alunos responderam ao mesmo tempo: A água, na parte de baixo, e a gasolina, na parte de cima.

Pedro: Mesmo exemplo do óleo! [Cristina entendendo que ele estava se referindo à mistura do óleo com a água]

Cristina: Mas aí tenho que saber a densidade do óleo.

Luís: (inaudível) ... a água e o álcool se misturam. [Cristina volta sua atenção à participação de Luís]

Cristina: O que faz um material se misturar com outro?

Aline: A propriedade [Cristina entendendo que ela estava dizendo que é uma propriedade dos materiais que faz com que eles se misturem ou não]

Cristina: Mas é a densidade? [Supondo que Aline estava entendendo o questionamento sobre tal propriedade ser a densidade]

Neste momento, a professora, que até então estava circulando entre as mesas dos alunos, foi à frente da sala e perguntou: Por que se misturam?, fazendo um gesto, como se estivesse com um frasco pequeno cheio de líquido dentro, balançando-o.

Marcelo: A água fica embaixo.

Cristina: Mas no começo elas se misturam [Cristina entendendo que Marcelo estava dizendo que parte do líquido no frasco "imaginário" era água e outra parte, a gasolina ou o óleo]

Elaine: É por causa do álcool que tem na gasolina [Tentando explicar por que os líquidos parecem se misturar começo]. A gasolina em si não mistura, só o álcool que tem na gasolina.

Cristina: $O K$, vocês estão me ensinando, está bem? Porque eu não sei [Referindo-se a não saber o que causa as misturas].

Daí para frente, a conversa continuou especulativa, tanto por parte da professora quanto por parte dos alunos, até que a aula terminou, não se chegando a nenhuma conclusão do porquê de certos líquidos parecerem se misturar e outros, não. 
Ao Cristina relatar para Selma essa discussão, Selma disse à Cristina que, em relação ao tema "misturas", esse assunto havia sido tratado nos sextos e sétimos anos com os alunos. Entretanto, continuou Selma, pesquisas em Química indicam que os estudantes resistem em aceitar que existem misturas heterogêneas, como, por exemplo, a água e a gasolina. Como é possível visualizar as duas substâncias, os alunos acham que isso não é mistura e consideram mistura quando, ao juntar duas substâncias, uma delas não é visualizada, como nas misturas homogêneas (o que não é correto, por exemplo: o sangue é uma mistura heterogênea e não visualizamos os materiais que o constituem). Segundo Selma, esses são alguns obstáculos no ensino de Ciências. Daí a proposta de recursividade do currículo abordando certos conceitos em diferentes situações e níveis (anos) escolares. Ainda, disse Selma, quando o conceito de densidade é trabalhado e os exemplos envolvem mistura de água com outra substância, o conceito de mistura é retomado. Retoma-se, então, o que são mistura homogênea e mistura heterogênea e a situação de que, nas misturas heterogêneas, como água e gasolina, a água fica no fundo do recipiente porque é mais densa que a gasolina (o mesmo acontece com água e o óleo).

É interessante observar que não só alguns alunos parecem mesmo compreender que o conceito de mistura está associado ao ajuntamento de duas substâncias em que uma delas não é visualizada, como também a professora Cristina. Não obstante, isso não foi impedimento para que a professora e os alunos especulassem sobre o assunto ou fizessem previsões de situações de mistura em termos de densidade, temas que, até então, lhes eram conhecidos apenas parcialmente, por meio de experiências anteriores ou mesmo informais, e que seriam retomados nas aulas de Ciências, alguns meses depois (vamos prosseguir com a história de Júlia e, depois, comentamos sobre as relações futuras, nos dois casos).

$\mathrm{Na}$ história de Júlia, tais "sementes" de relações futuras também podem ser identificadas a partir do extrato a seguir, do protocolo de relato de experiência elaborado por Selma após a visita à usina hidrelétrica com os alunos:

No dia 03 de novembro de 2005, realizei um trabalho de campo com uma turma de $8^{\circ}$ ano (...) na Hidrelétrica de Gafanhoto/CEMIG (...) Na chegada à hidrelétrica, a turma foi recebida pelo guia que nos informou o roteiro da visita. O primeiro ponto de parada foi o lago (represa) que armazena a água 
e essa passa por comportas feitas de alvenaria (cimento) que regulam sua entrada em um canal (...) Quando a turma aproximou do local deparou com o corpo de um cão morto flutuando na água [daí para frente a conversa se desenrolou como a descrevemos anteriormente] (...) Criou-se um "conflito cognitivo"; uma estranheza aos alunos. Como explicar aquele corpo do cão flutuando? Diante de algumas explicações dos alunos do tipo: "esse animal pode estar oco por dentro (idéia de menos massa, menos denso)", "pode ter sido comido em alguma parte por peixes carnívoros (idem)", uma aluna, Rejane, disse: "pode estar cheio de ar". Então perguntei de onde veio esse ar e porque ela associou essa flutuação do corpo do cão com o ar. Ela respondeu comparando com o que acontece com a tampinha de garrafa e o navio flutuando na água. São objetos formados de materiais mais denso, mas devido a forma (...) flutuam na água. Retornei a questão. Perguntei: Então o cão modificou sua forma? "Aparentemente não", responderam alguns. Mas não souberam explicar onde estava o ar no corpo do animal e qual a sua origem (...).

Nesse mesmo relato, Selma informou que, de volta à escola com os alunos, discutiram várias ideias sobre "afunda e flutua", em termos da fisiologia do pulmão de animais pulmonados, da forma ou área de contato de objetos na água e da densidade. E que, nessa discussão, tanto ocorreu que os alunos foram capazes de fazer relações entre os questionamentos da professora e o que aprenderam em anos anteriores, quanto especularam e fizeram previsões envolvendo aspectos do tema "afunda e flutua", que lhes eram ainda desconhecidos formalmente.

Com base na informação de Selma sobre o caráter recursivo do currículo de Ciências, sugerimos que tais especulações/previsões podem ser vistas como evidências de relações temporais passado-presente-futuro, em que passado corresponde aos conhecimentos prévios dos alunos em ambas as discussões guiadas por Cristina e Selma; "presente" corresponde às discussões sobre (i) proporcionalidade e densidade, na aula de Matemática e (ii) "afunda e flutua", na discussão na usina hidrelétrica; e "futuro" às discussão sobre (i) densidade e misturas, na aula de Matemática e (ii) "afunda e flutua" e as ideias discutidas entre Selma e os alunos na usina hidroelétrica e de volta à escola. Contudo, ainda que ambas as professoras e os alunos sustentassem um campo atencional compartilhado, como dizem Meira e Lerman, que envolveu relações temporais passado-presente-futuro e que possam tê-lo levado ao cultivo de processos ainda não desenvolvidos, não foi possível produzir evidências, nesses episódios, da construção, por parte dos alunos, desses processos ou de 
estruturas futuras de suas funções intelectuais sob as bases de suas experiências passadas e presentes. Em outras palavras, não dispomos de fundamentos para argumentar extensivamente aqui, até mesmo porque tais relações temporais não foram foco de investigação da pesquisa interdisciplinar em questão, o quanto ou não as especulações ou previsões feitas em torno das misturas e do "afunda e flutua" se concretizaram em progressos efetivos no entendimento dos temas por parte dos alunos. Ainda assim, podemos dizer que a participação dos alunos nas discussões foi, com certeza, diferente daquela em práticas passadas, nas quais tais temas foram abordados.

No que se refere às ideias de Meira e Lerman (2010) sobre “instrução oportunística" (p. 217), essas, no caso da pesquisa interdisciplinar, correspondem às ocasiões nas quais as professoras buscam se beneficiar de circunstâncias específicas para ensinar os alunos a conectar conceitos ou questões aparentemente não relacionadas, que elas tomam como dentro das possibilidades de entendimento dos alunos. Desse modo, vemos a instrução oportunística como sendo um componente essencial da ZDP e usamos isso para explicar como os alunos fizeram as relações temporais discutidas: a maneira receptiva como as professoras de Matemática e de Ciências agiram diante dos comentários dos alunos sobre seus próprios entendimentos foi fundamental para que esses (ou possíveis novos) entendimentos fossem produzidos. De fato, Cristina tomou a oportunidade apresentada pela resposta de Aline, "densidade", para (i) socializar com os alunos que a densidade de materiais físicos homogêneos, tais como a água, o ferro e a gasolina, é a constante de proporcionalidade direta entre massa e volume; e (ii) especular sobre misturas. De maneira similar, Selma se beneficiou do comentário de Júlia, "afunda e flutua", para discutir com os alunos propriedades da flutuação de corpos humanos, da estrutura dos pulmões e outras ideias relacionadas.

Outros dois comentários sobre ZDP relacionados à pesquisa das duas professoras e à pesquisa de Meira e Lerman merecem consideração: o primeiro refere-se à intencionalidade de ensino para criar ZDPs. Concordamos com os autores quando sugerem que objetivos instrucionais não são condições suficientes para produzir ZDPs. Contudo, evidências foram oferecidas no sentido de que os objetivos instrucionais das professoras-pesquisadoras, combinados com suas reflexões conjuntas e explícitas sobre a constituição de um ambiente de aprendizagem em 
Matemática e Ciências, no qual alunos e professoras foram agentes ativos das atividades e do progresso em direção a entendimentos comuns, têm mais chances de produzir ZDPs. O segundo comentário diz respeito à "fragilidade/instabilidade" das ZDPs. Meira e Lerman sugerem que a ZDP é tipicamente frágil quando se lida com crianças muito pequenas porque é difícil capturar e manter suas atenções. Isso é verdade se considerarmos que o foco dessas crianças, como Vygotsky (1978) sugere, são as brincadeiras. No caso de adolescentes, como ocorreu com os alunos participantes da pesquisa colaborativa entre Matemática e Ciências, o foco de atenção incide, muitas vezes, na expectativa de estudos futuros e aplicação dos estudos na vida, portanto, supostamente mais fácil de ser capturado. Tanto no episódio de Júlia quanto no de Aline interpretamos que ZDPs emergiram a partir das práticas discursivas ou cadeias de significação que se seguiram às conexões feitas por Aline (quando respondeu "densidade") e por Júlia (quando disse "afunda e flutua"). Essas práticas discursivas ou cadeias de significação, ou ainda, as discussões que se seguiram a elas, tiveram uma duração considerável: o tempo de duração das aulas de Matemática, relativas ao episódio de Aline, e boa parte da visita à usina hidrelétrica e de volta à escola (como informado por Selma), no episódio de Júlia. Isso é uma indicação de que essas ZDPs foram mais duráveis do que aquelas relatadas na pesquisa de Meira e Lerman, pelo simples fato de que os alunos de Selma e Cristina eram maduros o bastante para manter uma discussão, ao contrário dos pequeninos. Tendo uma considerável duração, tais discussões deram mais estabilidade à interpretação do surgimento das ZDPs; as discussões nos pareceram mais estáveis de se manter com adolescentes do que com os pequeninos. Por essa razão, sugerimos que as ZDPs criadas nos episódios de Aline e Júlia tiveram certa estabilidade e durabilidade, se comparadas aos episódios da pesquisa de Meira e Lerman.

\section{Considerações finais}

Neste artigo, relatamos uma pesquisa interdisciplinar realizada por duas professoras-pesquisadoras, uma de Matemática e outra de Ciências, junto a uma turma de alunos do nono ano do Ensino Fundamental, visando a subsidiar o conceito de Zona de 
Desenvolvimento Proximal como espaço simbólico, tal como concebem Meira e Lerman (2010). Buscamos contrastar aspectos evidenciados e argumentos desenvolvidos na pesquisa interdisciplinar e na pesquisa realizada por esses autores. Tomando como base dois episódios de aprendizagem, ilustramos como a emergência de uma ZDP pode ser evidenciada como espaço semiótico, de mediação simbólica, em termos de campos atencionais compartilhados entre professores e alunos, envolvendo relações passado-presente-futuro. Também procuramos mostrar como a "instrução oportunística" pode (e deveria, no nosso entender) ser promovida pelos professores como um componente fundamental da ZDP em ambientes de aprendizagem. Por fim, discutimos que a estabilidade e a manutenção das ZDPs podem estar mais associadas a ambientes educacionais compostos de alunos de maior maturidade, como nos anos finais do Ensino Fundamental e no Ensino Médio, por exemplo, se comparados a crianças menos maduras do Ensino Fundamental ou da Educação Infantil. Isso tudo nos leva a crer que o trabalho de Meira e Lerman (2010) oferece-nos, de fato, um conjunto útil e concreto de instrumentos operacionais para a investigação de ZDPs em ambientes de aprendizagem.

Como implicações pedagógicas, sugerimos que os exemplos discutidos possam trazer alguma contribuição para a reflexão sobre a prática dos professores, tanto os iniciantes quanto os já experientes, na medida em que as intervenções dos alunos que deram origem aos episódios aqui relatados são inúmeras em ambientes de aprendizagem, em particular nas salas de aula. Finalmente, sugerimos que a disponibilidade e a receptividade dos professores para ouvirem e agirem diante dos comentários dos alunos sobre seus próprios entendimentos estejam sempre presentes nessas reflexões, pois são fundamentais para o surgimento de possíveis ZDPs e, consequentemente, para a produção de (possíveis) novos entendimentos pelos alunos. 


\section{Referências}

BERNSTEIN, B. Pedagogy, symbolic control and identity: theory, research, critique. London, UK: Taylor and Francis, 1996.

BERNSTEIN, B. Social class and pedagogic practice. In: BALL, S. (Ed.) The Routledge Falmer reader in sociology of education. London, UK: Routledge Falmer, 2004, p. 196-217.

DANIELS, H.; WERTSCH, J.; COLE, M. The Cambridge Companion to Vygotsky. Cambridge: Cambridge University Press, 2007.

EVANS, J. Adults' mathematical thinking and emotions: a study of numerate practices. London, UK: RoutledgeFalmer, 2000.

FINO, C. N. Vygotsky e a Zona de Desenvolvimento Proximal (ZDP): três implicações pedagógicas. Revista Portuguesa de Educação, [S.1.], v. 14, n. 2, p. 273-291, 2001.

FRADE, C.; WINBOURNE P.; BRAGA, S. M. A mathematics-science community of practice: reconceptualising transfer in terms of crossing boundaries. For the Learning of Mathematics, [S.1.], v. 29, n. 2, p. 14-22, 2009.

HAZIN, I.; MEIRA, L. Múltiplas interpretações para a zona de desenvolvimento proximal na sala de aula. In: CORREIA, M. (Org.) Psicologia e escola: Uma parceria necessária Campinas, SP: Alínea, 2004. p. 45-60.

HOWE, C.; NUNES, T.; BRYANT, P. Intensive quantities: why primary school mathematics needs them', Teaching and Learning Research Programme, research briefing 10, London, UK,TLRP, 2005. Disponível em:

http://www.tlrp.org/pub/documents/HoweRB(no10)_Jul05.pdf. Acesso em: 05 jul. 2009.

LAVE, J. Cognition in practice. New York, NY: Cambridge University Press, 1988.

LAVE, J.; Wenger, E. Situated learning: legitimate peripheral participation. New York, NY: Cambridge University Press, 1991.

MEIRA, L.; PINHEIRO, M. Produção de sentidos no uso que se faz de gráficos. Estudos de Psicologia, Natal, v. 12, p. 135-152, 2007.

MEIRA, L.; LERMAN, S. Zones of Proximal Development as fields for communication and dialogue. In: C. LIGHTFOOT; M. C. D. P. LYRA. (Org.). Challenges and strategies for studying buman development in cultural contexts. Rome: Information Age Pub Inc. 2010. p. 199-219.

NEWMAN, F; HOLZMAN, L. Lev Vygotsky: revolutionary scientist. London, UK: Routledge, 1993.

PRESTES, Z. R. Quando não é quase a mesma coisa - análise de traduções de Lev Semionovitch Vigotski no Brasil, Repercussões no campo educacional. 295 f. Tese (Doutorado em Educação) - Faculdade de Educação, Universidade de Brasília, Brasília, 2010.

VALSINER, J.; VAN DER VEER, J. The encoding of distance: the concept of the "zone of proximal development" and its interpretations. In: COCKING, R. R.; RENNINGER, K. A. (Ed.) The development and meaning of psychological distance. Hillsdale, NJ: Lawrence-Erlbaum, 1993. p. 35-62.

VAN DER VEER, R.; VALSINER, J. Understanding Vygotsky: a quest for synthesis. Oxford: Basil Blackwell, 1991.

VYGOTSKY, L. Mind in society: the development of higher psychological processes (M. 
Cole, V. John-Steiner, S. Scribner, \& E. Souberman, Ed.). Cambridge, MA: Harvard University Press, 1978.

WENGER, E. Communities of practice: learning, meaning and identity. Cambridge, UK: Cambridge University Press, 1998.

\section{Notas}

1 Apoio CNPq.

2 Versão atualizada e ampliada do artigo: MEIRA, L. E LERMAN, S. The Zone of Proximal Development as a Symbolic Space, Social Science Research Papers, London, South Bank University, v. 1, n. 13, p. 1-40, 2001.

3 A professora-pesquisadora de Matemática a quem nos referimos é a primeira autora do presente artigo. Para facilitar a escrita e o desenvolvimento de nossos argumentos, adotaremos a seguinte estratégia textual: quando quisermos nos referir ao nosso papel de autores deste artigo, usaremos a primeira pessoa do plural. Quando estivermos nos referindo ao papel da primeira autora como professora-pesquisadora, usaremos a terceira pessoa do singular.

4 Traduzido para o português como $A$ formação social da mente.

5 Segundo Vygotsky, a interiorização é o processo de reconstrução interna de ações ou operações partilhadas no âmbito intersubjetivo, social, entre pessoas.

6 A título de informação sobre o significado-uso do termo ZDP da forma como Vygotsky o teria utilizado nessa segunda formulação, sugerimos a leitura da tese de doutorado de Zoia Ribeiro Prestes (2010), defendida na Universidade de Brasília. Com base na compreensão do termo russo zona blijaichego razvitia, a autora aponta as confusões nas traduções desse termo e discute os equívocos em sua interpretação. Prestes defende que a tradução que mais se aproxima do termo zona blijaichego razvitia é "zona de desenvolvimento iminente, pois sua característica essencial é a das possibilidades de desenvolvimento, mais do que do imediatismo e da obrigatoriedade de ocorrência, pois se a criança não tiver a possibilidade de contar com a colaboração de outra pessoa em determinados períodos de sua vida, poderá não amadurecer certas funções intelectuais e, mesmo tendo essa pessoa, isso não garante, por si só, o seu amadurecimento” (p. 173). Apesar de mantermos o termo zona de desenvolvimento proximal no presente artigo, o leitor verá que compartilhamos com Prestes suas considerações sobre tal característica de uma zona blijaichego razvitia.

7 Por esfera formal estamos nos referindo àquela em que há intencionalidade institucional ou institucionalizada de alguma aprendizagem, tal como a escola, a família, a igreja, entre outras. Já a esfera informal não estaria atrelada a esse aspecto institucionalizado: por exemplo, um carpinteiro pode aprender e usar algumas estratégias e procedimentos matemáticos por força de uma necessidade pessoal, por experimentação.

8 Linguagem, ferramentas, tecnologias, meios de comunicação, convenções, entre outros. 
9 Esta tipologia é explicita em Meira e Lerman (2001), embora nem tanto na edição revisada do estudo, publicada como Meira e Lerman (2010), versão que guiou a maior parte de nossos comentários neste artigo.

10 Meira e Lerman usam o termo linguagem para incluir as falas e os gestos. Quando querem se referir a uma comunicação somente verbal, eles usam o termo fala.

$11 \mathrm{O}$ ambiente desta pesquisa, incluindo as características da escola, seus alunos e professores são detalhados em Frade, Winbourne e Braga (2009).

12 As gravações das aulas de Cristina mostram uma mudança na maneira como ela conversou com os alunos sobre proporcionalidade, incorporando uma linguagem verbal e científica. Ela já havia estudado os materiais de Selma e discutido com a colega seu entendimento desses materiais. Cristina procurou conversar sobre densidade, em sua sala de aula, usando os termos e expressões que aprendera com Selma. No caso de Selma, que será relatado mais adiante, uma mudança similar pode ser vista nos registros de suas aulas.

Recebido: 04/11/2010

Aprovado: 06/10/2011

Contato:

Universidade Federal de Minas Gerais

Faculdade de Educação

Avenida Antonio Carlos, 6627

CEP $31270-901$

Belo Horizonte, MG

Brasil 